OPEN ACCESS

Edited by: Elena M. Kramer, Harvard University, USA

Reviewed by: Yasuyuki Onodera, Hokkaido University, Japan Edward Michael Golenberg, Wayne State University, USA

*Correspondence:

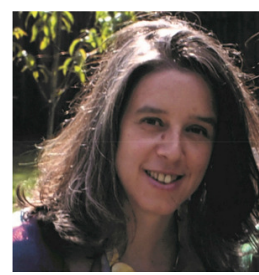

Maria M. R. Costa

is an Assistant Professor in the Biology Department of the University of Minho, Portugal. The lab is currently

studying different transcriptional networks of genes that regulate floral

organogenesis and how some of these genes have contributed for the establishment of novel morphologies during evolution.

manuela.costa@bio.uminho.p

Received: 06 November 2015

Accepted: 30 January 2016

Published: 19 February 2016

Citation:

Sobral R, Silva HG, Morais-Cecilio L and Costa MMR (2016) The Quest for Molecular Regulation Underlying Unisexual Flower Development. Front. Plant Sci. 7:160 doi: $10.3389 /$ fpls.2016.00160

\section{The Quest for Molecular Regulation Underlying Unisexual Flower Development}

\author{
Rómulo Sobral ${ }^{1}$, Helena G. Silva ${ }^{1}$, Leonor Morais-Cecilio ${ }^{2}$ and Maria M. R. Costa ${ }^{1 *}$ \\ ${ }^{1}$ Biosystems and Integrative Sciences Institute, Plant Functional Biology Centre, University of Minho, Braga, Portugal, \\ ${ }^{2}$ Departamento de Recursos Naturais Ambiente e Território, Linking Landscape, Environment, Agriculture and Food, Instituto \\ Superior de Agronomia, Universidade de Lisboa, Lisboa, Portugal
}

The understanding of the molecular mechanisms responsible for the making of a unisexual flower has been a long-standing quest in plant biology. Plants with male and female flowers can be divided mainly into two categories: dioecious and monoecious, and both sexual systems co-exist in nature in ca of $10 \%$ of the angiosperms. The establishment of male and female traits has been extensively described in a hermaphroditic flower and requires the interplay of networks, directly and indirectly related to the floral organ identity genes including hormonal regulators, transcription factors, microRNAs, and chromatin-modifying proteins. Recent transcriptomic studies have been uncovering the molecular processes underlying the establishment of unisexual flowers and there are many parallelisms between monoecious, dioecious, and hermaphroditic individuals. Here, we review the paper entitled "Comparative transcriptomic analysis of male and female flowers of monoecious Quercus suber" published in 2014 in the Frontiers of Plant Science (volume 5 |Article 599) and discussed it in the context of recent studies with other dioecious and monoecious plants that utilized high-throughput platforms to obtain transcriptomic profiles of male and female unisexual flowers. In some unisexual flowers, the developmental programs that control organ initiation fail and male or female organs do not form, whereas in other species, organ initiation and development occur but they abort or arrest during different species-specific stages of differentiation. Therefore, a direct comparison of the pathways responsible for the establishment of unisexual flowers in different species are likely to reveal conserved modules of gene regulatory hubs involved in stamen or carpel development, as well as differences that reflect the different stages of development in which male and/or female organ arrest or loss-of-function occurs.

Keywords: Quercus suber, male and female flower development, unisexuality, monoecy, RNA-seq, transcriptomics

\section{INTRODUCTION}

Unisexuality is considered to be an important transition in the evolutionary history of angiosperms (Barrett, 2010). The emergence of separate male and female traits in the same individual (monoecy) or in different individuals (dioecy) has evolved many times in ca $10 \%$ of angiosperms species from a hermaphroditic ancestral state (Charlesworth and Charlesworth, 1978; 


\section{KEY CONCEPT 1 | Monoecy and Dioecy}

Two major unisexual systems occur in the angiosperms: Dioecy-sexual system in which individual plants have either male or female flowers. Monoecy-sexual system in which both male and female flowers coexist in the same individual.

Tanurdzic and Banks, 2004). Here, we present a focused review of our current understanding on the different mechanisms underlying unisexual flower development. We will focus our attention in high-throughput transcriptomic studies using unisexual flowering species, which is providing large amounts of information and may uncover the molecular mechanisms responsible for male and female unisexual flower differentiation and determination.

\section{THE MAKING OF MALE AND FEMALE ORGANS}

In angiosperms, endogenous and environmental cues control highly specialized gene expression programmes that establish the male and female organs within a flower. These mechanism have been extensively studied in hermaphrodite flowers and led to the elaboration of the ABCDE model, in which each class of genes is recruited in the flower meristem to specify the identity of sepals, petals, stamens, carpels, and ovules (Bowman et al., 1989, 1993; Coen and Meyerowitz, 1991; Flanagan et al., 1996; Liljegren et al., 2000; Pelaz et al., 2000). In Arabidopsis thaliana, and in other species with hermaphrodite flowers, B combined with the $\mathrm{C}$ and $\mathrm{E}$ class genes specify stamen identity, whereas $\mathrm{C}$ and $\mathrm{E}$ genes, together, specify carpel identity (for a review see AlvarezBuylla et al., 2010; Litt and Kramer, 2010; Bowman et al., 2012). Homologs for the ABCDE model genes have been identified and associated with the male and female organ differentiation in many hermaphrodite species in what seems to be a conserved molecular mechanism (Theissen and Melzer, 2007; Greenup et al., 2009; Andrés and Coupland, 2012; Bowman et al., 2012). These genes seem to be also playing a role in the differentiation of unisexual organs in dioecious and monoecious species (Kater et al., 2001; Sather et al., 2010).

The developmental mechanisms that lead to flowers with different sex may require differential redeployment of the ABCDE regulatory network. Differences in the regulation of upstream effectors of the homeotic regulators may originate flowers that fail to initiate female or male organ primordia being unisexual by inception-Type II flowers (Mitchell and Diggle, 2005). On the other hand, many flowers become unisexual after flower organs are specified, but during the process of

KEY CONCEPT 2 | Type I flowers, androecium, gynoecium, and Type II flowers

Different pathways that originate gender dimorphism: Type I flowers are bisexual at initiation and become unisexual by termination of the development of the androecium (the male reproductive organs) or gynoecium (the female reproductive organs). In Type II flowers, sex differentiation occurs before stamen or carpel primordia initiation (Diggle et al., 2011). differentiation, carpel or stamen abortion or arrest occur and the organs become non-functional (Type I flowers). There is however some difficulty in distinguish morphologically a true Type II flower, that fails to initiate the developmental programs of the undesired organ, from a Type I flower that suffers organ abortion or arrest at a very early stage of organ initiation and development (Mitchell and Diggle, 2005).

The extensive utilization of forward and reverse genetics in A. thaliana, with more recent approaches such as microarrays, ChIPseq, and RNA-seq, led to the identification of hormones, transcription factors, microRNAs, and chromatin-modifying proteins as being also involved in the establishment of male and female traits in a hermaphroditic flower (reviewed in Ó’Maoiléidigh et al., 2014; Chávez Montes et al., 2015). Therefore, the processes during stamen and carpel differentiation require the interplay of extensive regulatory networks, that are directly or indirectly related to the floral organ identity genes (Wellmer et al., 2004; Zhang et al., 2005). Hence, organ abortion or loss-of-function in unisexual flowers in different species may involve a mutation or differential regulation in any of the many regulatory genes that control androecium or gynoecium differentiation, in what probably reflects the multiple evolutionary origins of dioecy and monoecy (Ainsworth, 2000). Diggle et al. (2011) summarized the literature on unisexual flower development, and recognized four stages of sexual organ loss of organ function: before the initiation of stamen or carpel primordia (stage 0 ); early in stamen or carpel development (stage 1); pre-meiosis (stage 2); and post-meiosis (stage 3) (Figure 1). Among the 292 taxa surveyed by these authors, loss-of-sexualorgan function occurs with equal frequency at each of the four stages in both male and female flowers, in monoecious and dioecious taxa. The arrest of development does not tend to occur preferentially at any particular stage, suggesting that there are no key stages of androecial or gynoecial development that are affected repeatedly upon the evolutionary origin of unisexual flowers. Therefore, a direct comparison of the pathways responsible for the establishment of unisexual flowers in different species is likely to reveal conserved modules of gene regulatory hubs involved in stamen or carpel development, as well as differences that reflect the different stages of development in which male and/or female organ arrest or loss-of-function occur.

\section{QUERCUS SUBER: A CASE STUDY}

With the aim of uncovering the developmental programs underlying the establishment of female and male organs in unisexual flowers of a monoecious species, a recent study published in Frontiers of Plant Science 2014, 5:599 has identified differentially expressed genes during the development of male and female flowers of Quercus suber (cork oak), an ecologically and economically important Mediterranean tree.

In $Q$. suber, female inflorescences arise in spikes, with three to five individual flowers (Figures 2A,B), on the axil of the new leaves. Female flowers are included in a cupule and contain three carpels, with two ovules each (Boavida et al., 1999). Male flowers are organized in catkins that emerge in reproductive buds of the previous growth season or at the base of the branches of the 


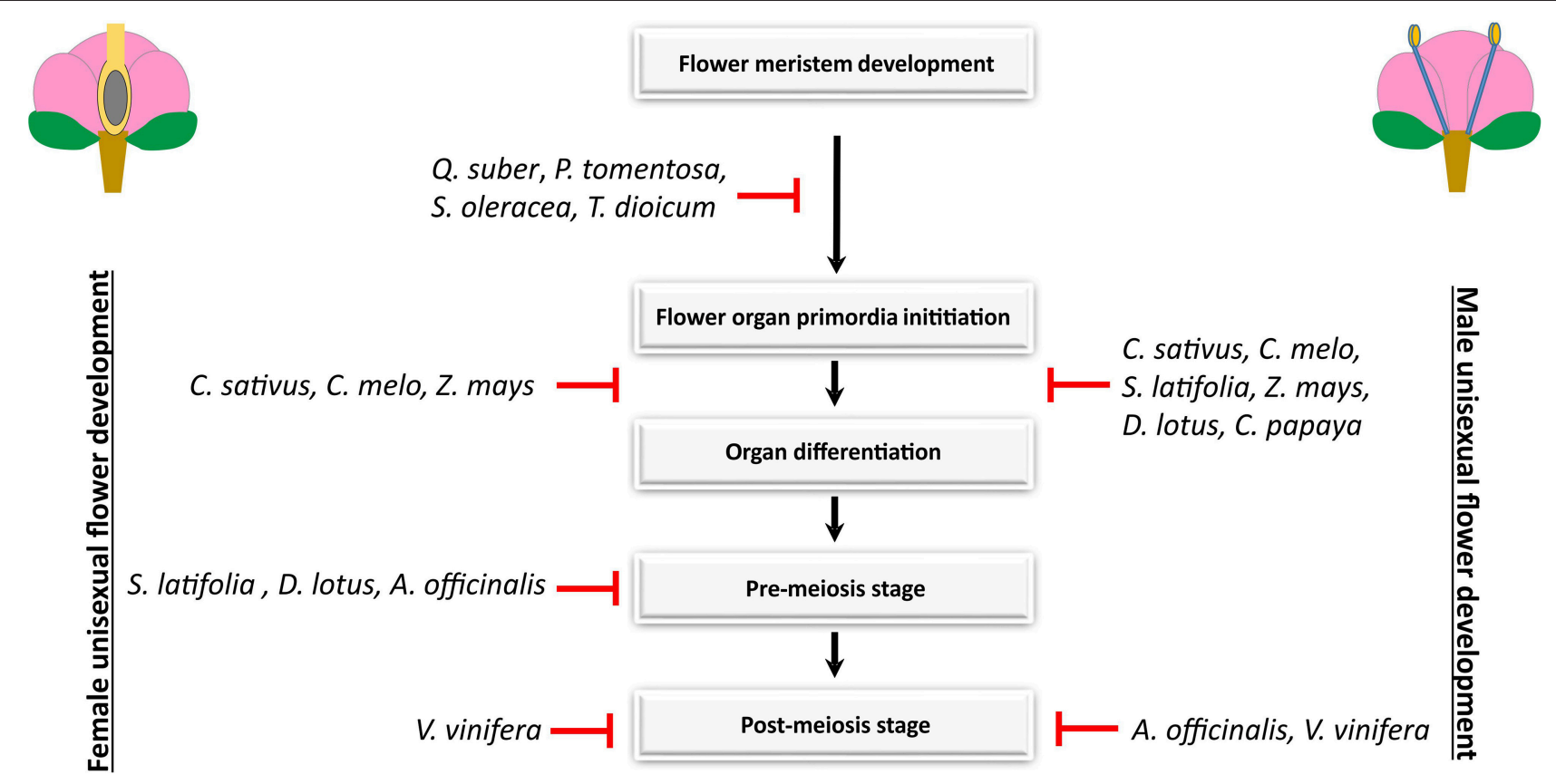

FIGURE 1 | Developmental path to unisexuality in male and female flowers in monoecious and dioecious species. In Quercus suber, Populus tomentosa, Spinacea oleracea, and Thalictrum dioicum, sex differentiation occurs prior to flower organ primordia initiation (Varela and Valdiviesso, 1996; Boavida et al., 1999; Sheppard et al., 2000; Di Stilio et al., 2005; Pfent et al., 2005; Sather et al., 2010). In Carica papaya, the pistil degeneration is clear at early stages of organ development in male flowers but female flowers have no traces of stamens (Ronse Decraene and Smets, 1999). Stamen and pistil development in Cucumis sativus, Cucumis melo, and Zea mays arrests during early organogenesis (Le Roux and Kellogg, 1999; Bai et al., 2004; Boualem et al., 2008). The abortion of stamens in Silene latifolia and Diospyros lotus occurs later than the abortion of the pistil, at a pre-meiotic stage (Grant et al., 1994; Akagi et al., 2014). In Asparagus officinalis, the arrest of stamens occurs somewhat early than the arrest of pistils (Caporali et al., 1994). Stamen and pistil degeneration in Vitis vinifera occurs at the post-meiotic stage (Caporali et al., 2003).

current season. Each individual catkin contains 15-25 staminate flowers (Figures 2C,D). The staminate flowers present a perianth with four to six tepals with an equal or double number of anthers that do not burst simultaneously (Boavida et al., 1999). Q. suber flowers are thought to be unisexual by inception, as there is no morphological evidence of organ initiation or abortion of the missing organs (Varela and Valdiviesso, 1996; Boavida et al., 1999). Interestingly, Q. suber is a protandrous species, with male catkins developing in early spring and sometimes also in autumn, whereas female flowers appear in spring, more than a month later than the male ones, and only get fully developed a few months later, if pollinated. Therefore, this species presents spatial separation of male and female reproductive organs, but by delaying the maturation of the carpels, it presents also a temporal separation, as there is little overlap between staminate and pistillate phases of an individual plant. This was previously referred to as "temporal dioecism" (Cruden and HermannParker, 1977) and it exists in many species as a means to achieve

KEY CONCEPT 3 | Protandrous system and progamic phase

A protandrous system can be defined as a sexual strategy in which the development of male flowers occurs before the development of the female flowers. A progamic phase is the period that spans between pollination and fertilization. outbreeding. Another characteristic trait of this species is its long progamic phase. At the time of pollination, the ovary is still undifferentiated and the transmitting tissue extends only to the base of the styles. Usually, the pollen tube germinates and its growth is arrested for 6 weeks at the base of the style, overlapping with ovule differentiation (Boavida et al., 1999; Kanazashi and Kanazashi, 2003). Therefore, to capture the complete development of the female flower up to the maturation of the ovules, the tissues have to be sampled up to 6 weeks after pollination.

Using an RNA-seq approach, Rocheta et al. (2014) generated distinct cDNA libraries for early and late stages of male and female flower development of $Q$. suber providing a highthroughput study on female and male flowers of this monoecious tree, hence, within a uniform genetic background. In this study, six developmental stages of male and female cork oak flowers were included (Figures 2A-D) to cover early stages of organ development (1M and $1 \mathrm{~F}$ ), up to pollen release in male flower and pollination in female flowers ( $2 \mathrm{M}$ and $2 \mathrm{~F}$, respectively). As it is difficult to track which female flowers are successfully pollinated and, hence, proceed to complete the differentiation of the embryonic sac, these stages of female flower development after pollination were not sampled. This Q. suber transcriptomic study revealed differential accumulation of transcripts in male and female flowers and in different stages of flower development 


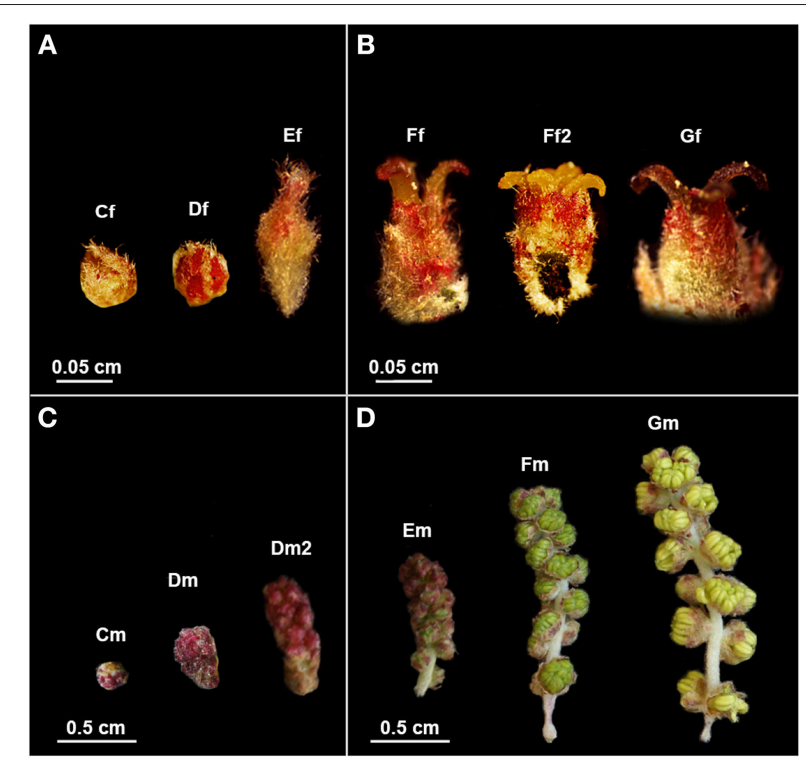

E

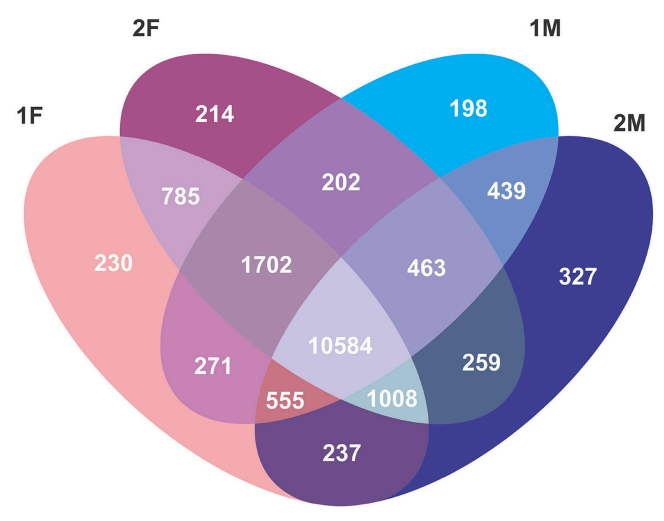

FIGURE 2 | Quercus suber female and male flowers in different developmental stages used in the RNA-seq and a description of the unique and differentially expressed gene between libraries. (A) Early and (B) late stages of female flower development used in pools $1 \mathrm{~F}$ and $2 \mathrm{~F}$, respectively. (C) Early and (D) late stages of male flower development used in pools $1 \mathrm{M}$ and $2 \mathrm{M}$, respectively. (Cf) female bud enclosed by protective scales; (Df) female reddish bud with open scales; (Ef) elongation of the spike axis and the emergency of the first pair of flowers; (Ff) female flower showing distinct, erect, yellow stigmas with curved pinkish/brownish tips; (Ff2) flower with shining yellow and viscous pattern stigmas in clear divergent position; (Gf) female flower with closed stigmas that lost the receptivity, exhibiting a dark brown color. $(\mathrm{Cm})$ catkin with red round shape due to the tight clustering of the flowers; (Dm) elongated cluster of male flowers; (Dm2) pendent catkin with some individualized flowers; (Em) male flowers with the anthers individualized; (Fm) flowers with individualized green/yellow anthers where pollen shedding begins; (Gm) catkin with male flowers in full anthesis. (E) Venn diagram indicating the number of exclusive and shared transcripts of early and late developmental stages of Quercus suber flower. Four EST projects were generated from four-specific RNA pools, two for female flowers (1F and $2 \mathrm{~F}$ ) and two for male flowers ( $1 \mathrm{M}$ and $2 \mathrm{M})$, covering either early ( $1 \mathrm{~F}$ and $1 \mathrm{M})$ or the late (2F and 2M) developmental stages (Rocheta et al., 2014).

(Figure 2E). The analysis of the cDNA libraries obtained showed that there were 230 unique contigs for the early $(1 \mathrm{~F})$ and 214 contigs unique for the late $(2 \mathrm{~F})$ stages of female flower development. The 1F unique contigs might correspond to genes controlling early flower development, whereas the $2 \mathrm{~F}$ unique contigs might be associated with stigma maturation. Accordingly, there were 198 contigs unique in the early stages of male flower development $(1 \mathrm{M})$, most probably involved in early stages of anther development and 327 contigs specific for the late stages $(2 \mathrm{M})$ that could be indicative of genes controlling pollen development and maturation. Further analysis showed that the majority of the unique transcripts in the male libraries are organ specific, not having been detected in other organs of the plant, and probably reflect the uniqueness of the stamen regulatory network. On the contrary, most of the transcripts found overrepresented in the female libraries are also expressed in other organs (root, leaves, buds, and fruits).

Diggle et al. (2011) stated that, in unisexual flowers that do not initiate the undesired organs, the likely sex-determinant genes should be among the factors in the short pathway from floral initiation to organ identity establishment, particularly the $\mathrm{B}$ and $\mathrm{C}$ class organ-determinacy genes and their regulatory effectors. Studies in species that are dioecious by inception, Spinacea olearacea and Thralictrum dioicum, or are monoecious by early organ abortion, Elias guineensis, are clear examples that demonstrate how changes in the regulation of homeotic regulators can initiate different sex-developmental pathways (Jaligot et al., 2004; Adam et al., 2005; Sather et al., 2010; Larue et al., 2013). In S. oleracea, B class genes are expressed before the initiation of floral organ primordia in a sex-specific manner and its suppression in male flowers by RNAi originates a conversion of male into female flowers (Sather et al., 2010). Similar results were obtained in $T$. dioicum, where targeted silencing of a B class gene ( $T d P I)$ by virus-induced gene silencing also resulted in homeotic conversion of stamens into carpels (Larue et al., 2013). The oil palm Elaeis guineensis has staminate unisexual flowers by inception and pistillate flowers that contain a pair of aborted stamens (Adam et al., 2005). An E. guineensis floral variant known as mantled, commonly observed in palms produced by in vitro micropropagation is characterized by the homeotic transformation of the fertile or sterile androecium into pseudocarpels resembling B class mutants (Jaligot et al., 2004; Adam et al., 2005). The mantled phenotype was associated with the DNA hypomethylation of a LINE retrotransposon (Karma) present in the intron of the $\mathrm{B}$ class gene DEFICIENS leading to alternative splicing and premature transcript termination (OngAbdullah et al., 2015).

In Q. suber, the three B-class transcripts (QsAPETALA3, QsPISTILLATA, and QsTM6) were more abundant in the male flower libraries, whereas QsAGAMOUS (the C-class organ identity gene) had a similar level of expression in male and female libraries (Rocheta et al., 2014). Down-regulation of the B-class genes may explain the absence of stamens during pistillate flower development. It would be interesting to address the function of the B-class genes in Q. suber in future studies, such as the analysis of their expression domain within the male flower meristem, how their transcripts are temporally and spatially regulated in young male and female flower primordia and if these genes are under epigenetic regulation that could lead to differential expression between the different flower types. There are few 
high-throughput transcriptomic studies comparing male and female flowers by inception. An example is a study made available by Song et al. (2013a) that performed a microarray analysis on male and hermaphrodite flowers of an andromonoecious poplar in a late stage of development prior to pollination (male organs of male flowers were compared to the female organs of the hermaphrodite flowers). These authors acknowledged the advantages of studying different flower ontogenic processes on the same plant, thus having the same genetic background. The transcription profile of several genes in poplar was very similar to the one observed in Q. suber for late stages of flower development (e.g., QsAGL24 over-represented in the male organs and QsCOL9 in the female ones). It would be interesting to investigate if in early stages of organ development there is a similar transcription profile between Q. suber, P. tomentosa, S. olearacea, and $T$. dioicum. The data provided by Rocheta et al. (2014) might be important to complement future studies in other trees species and, therefore, could create an opportunity to uncover genes that are involved in reproductive biology of species in which sex differentiation occurs before or during the reproductive organ primordia initiation.

\section{TRANSCRIPTOMIC ANALYSIS OF UNISEXUAL FLOWERS IN OTHER SPECIES}

Successful functional studies in a non-model tree species, such as cork oak, are difficult to perform, due to several limitations that are transversal to many non-model species: a lack of a sequenced genome, a recalcitrant behavior to transformation and a long life cycle, and for many years not much was known about the transcription profiling that underlie their developmental programs.

The recent availability of high-throughput technologies has allowed the generation of large-scale data in non-model species. Comparative global transcriptome analysis between studies may reveal conserved gene regulatory modules involved in the differentiation of male and female organs that underlie the development of unisexual flowers. However, to make the most of transcriptomic studies, a comparison between studies should take into account the type of biological material utilized, in particular, the chosen developmental stages used for RNA extraction, the sexual strategy of each species (e.g., monoecy or dioecy), the type of developmental events that establish unisexuality (unisexual by inception or by organ abortion), and the type of highthroughput platform and the pipeline of bioinformatic data treatment (Table 1).

In the past decade, several high-throughput transcriptomic studies comparing male and female flowering structures from different species have been made available, and to which the results obtained by Rocheta et al. (2014) may be compared against. An initial survey of the available transcriptomic studies (see references within Table 1) reveals that some authors are particularly interested in addressing the regulation of potential candidates within certain groups of genes, particularly, hormone-related genes, genes linked to sexual chromosomes, transcriptional regulatory factors, miRNAs, and epigenetic modifiers. Other authors describe modules of genes that are differentially co-expressed and may represent a particular transcriptional network active in a specific stage of flower organ development.

\section{HORMONAL REGULATION}

Hormones play wide-ranging roles in the development and physiological processes throughout the lifetime of an angiosperm plant from seed to senescence. In the past century several authors have emphasized the influence of hormonal regulation in sex determination (e.g., Rudich et al., 1972) but an overall mechanism linking hormone signaling and sex determination has not been possible mainly due to the ambiguous action of hormones, which in many cases is species dependent. In Q. suber, the great majority of the genes associated with auxin, ethylene, and cytokinin regulatory pathways are over-represented in the female flowers. In opposition, several gibberellins-related transcripts were found exclusively in the male flowers, being expressed both in early and late stages of development, indicating a role in male floral primordia and in anther differentiation (Rocheta et al., 2014). The masculinization role of gibberellins (Cheng et al., 2004; Plackett et al., 2011; Zhang et al., 2014) is, however, not consensual as genes promoting ear development in maize are associated with the gibberellin biosynthesis pathway (Bensen et al., 1995; Winkler and Helentjaris, 1995; Helliwell et al., 2001). The same happens with ethylene, as in species such as maize, cucumber, or melon, the feminizing role of ethylene appears to be conserved (Boualem et al., 2008; Eveland et al., 2010; Sun et al., 2010; Liu et al., 2015), whereas in Citrullus lanatus ethylene has a masculinizing effect (Rudich, 1990). Despite a lack of a universal consensual role in flower masculinization or feminization for each particular hormone, in the different transcriptomic studies surveyed, groups of hormone-related transcripts have been identified as being differentially expressed between flower types, which suggests a definite role for hormones in sexual organ differentiation and should be seen as species specific (Guo et al., 2010; Wu et al., 2010; Song et al., 2013a; Ramos et al., 2014; Rocheta et al., 2014; Gao et al., 2015).

\section{TRANSCRIPTIONAL REGULATION}

Differential regulation of transcription factors (TF) has a pivotal role in the control of mechanisms that control organ development (Latchman, 1997). There are several examples of how individual transcription factors can control sex developmental pathways and organ differentiation in unisexual species (Chuck et al., 1998, 2007; Martin et al., 2009). Taking into consideration the functional importance of TF, Rocheta et al. (2014) described several unique and differentially expressed TF between the male and female libraries and grouped them in families according to their homologies. Other high-throughput studies followed the same reasoning and pointed out amongst the differential expressed genes in each study several transcription factors that could be determinant for sex differentiation (e.g., Guo et al., 2010; Wu et al., 2010; Huang et al., 2013; Gao et al., 


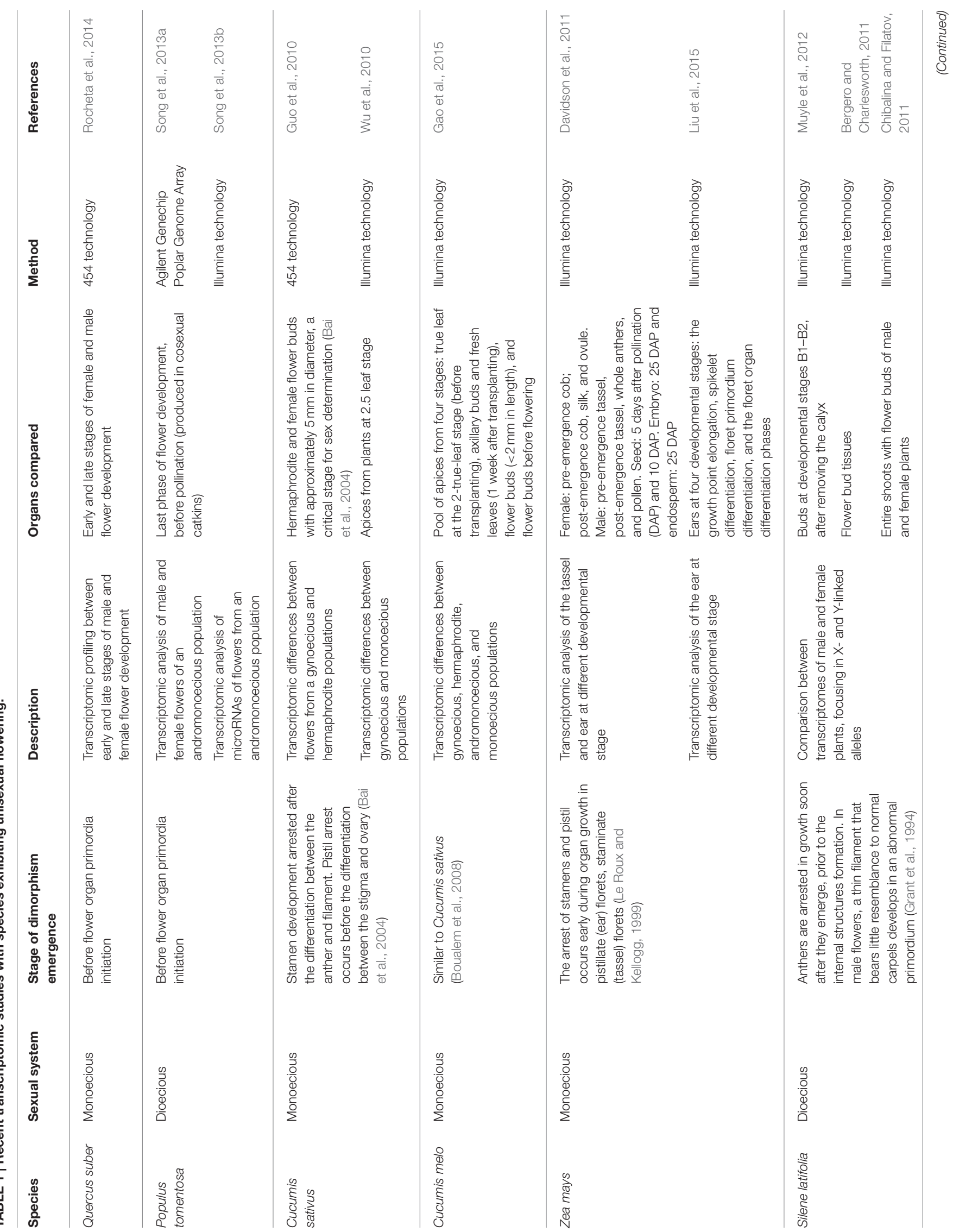




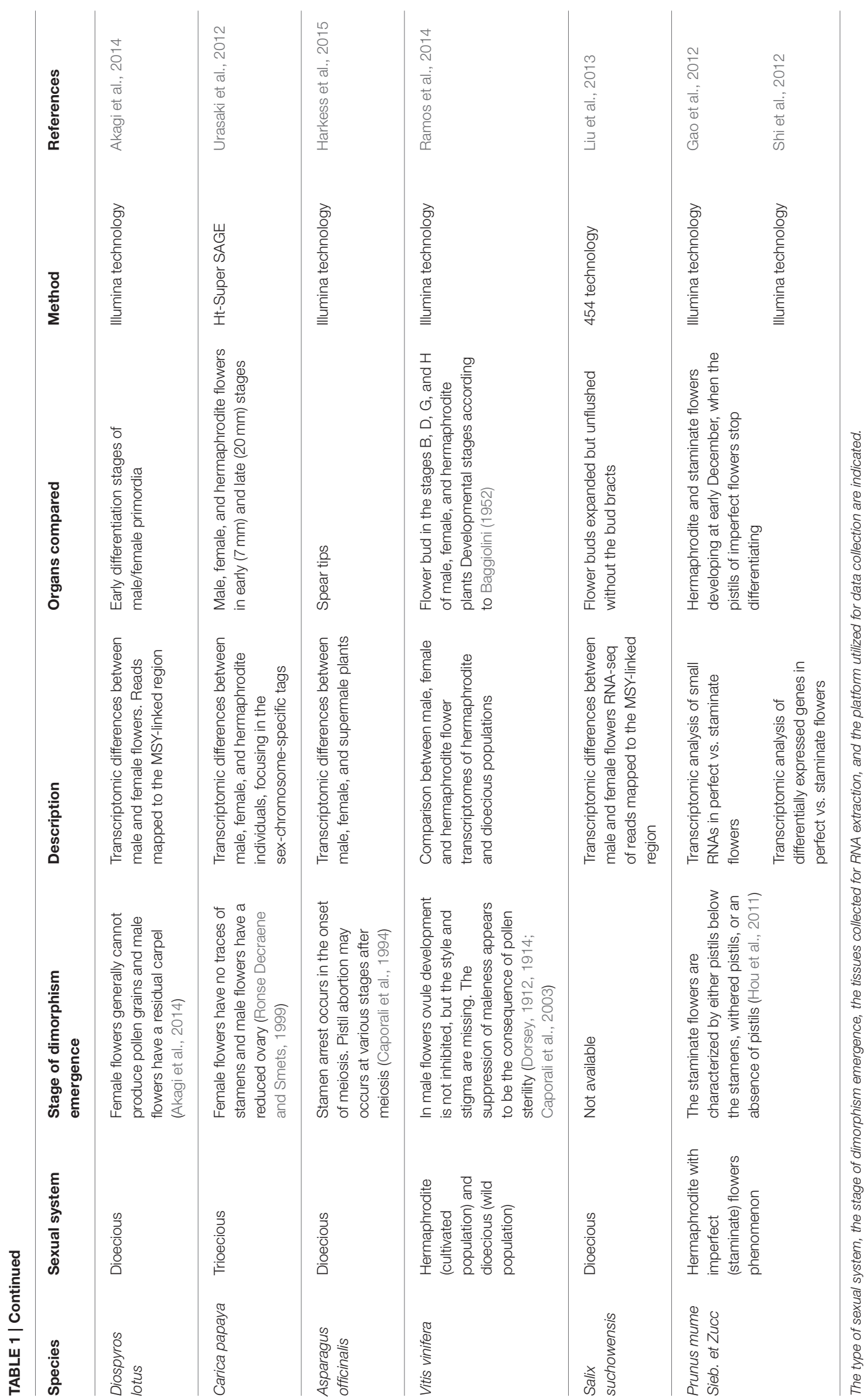


2015; Liu et al., 2015). In the Cucurbitaceae, sex-determination genes associated to the ethylene biosynthesis pathway are partly conserved (Yamasaki et al., 2001; Mibus and Tatlioglu, 2004; Knopf and Trebitsh, 2006; Martin et al., 2009; Li et al., 2012) but little is known about the transcriptional machinery associated to sex determination. To fill up this gap, Wu et al. (2010), Guo et al. (2010), and Gao et al. (2015) conducted RNAseq studies in the genus cucumber using similar strategies. In C. sativus, male flowers from monoecious individuals were compared to female flowers from gynoecious individuals, whereas in C. melo a broader range of genotypes were used (Gao et al., 2015). The number of differential expressed genes varied depending on the study, maybe reflecting different sequencing platforms or different methods used for data analysis. Using 454 pyrosequencing technology, Guo et al. (2010) identified 90 genes up regulated in female flowers and 124 genes in the bisexual flower, whereas Wu et al. (2010) using Solexa technology identified a greater amount of differentially expressed genes (143 up-regulated and 600 down-regulated in female flowers). Several identified homologs for transcription factors (BEL-1 LIKE HOMEODOMAIN1, PHYTOCHROME INTERACTING PROTEIN3, WRKY, MYC2) were also differentially expressed in the Q. suber libraries (Rocheta et al., 2014). Gao et al. (2015) performed a transcriptomic survey of melon inflorescences from individuals with different sexual habits (monoecious, andromonoecious, hermaphrodite, and gynoecious). Using Illumina technology, four flower libraries were obtained for each genotype and further analysis allowed the identification of genes unique to each library. Particularly, a homolog for PIF3 that is exclusive to female flowers (similarly to Q. suber) was identified. PIF3 codes for a protein that in Arabidopsis interacts with DELLA proteins (Feng et al., 2008) and, thus, also suggests the involvement of gibberellins in sex determination in cucumber. The TFs common to the aforementioned studies were zinc fingers that have been previously associated with the masculinization of C. melo flowers (Martin et al., 2009). Interestingly, all the zinc fingers differentially expressed in Q. suber are over represented in the female libraries (Rocheta et al., 2014). Regarding the Cucurbitaceae, it would be very interesting to analyze the data using a similar pipeline in order to identify common transcriptional regulation networks.

Several high-throughput transcriptomic studies have been performed to study the reproductive development of maize (Wang et al., 2009; Zhu et al., 2009; Eveland et al., 2010; Davidson et al., 2011; Kakumanu et al., 2012; Sekhon et al., 2013; Liu et al., 2015). A recent RNA-seq study analyzed solely the formation of the female flower (Liu et al., 2015). Four developmental stages were analyzed (Table 1) that ranged from the undetermined meristem to floret organ differentiation. Several differentially expressed genes were identified in pairwise comparative analysis between the different stages of development (Table 1), including a group of transcription factors whose expression in specific stages could be crucial for female flower development. Davidson et al. (2011) compiled an extensive transcriptomic data on several stages of the maize reproductive development. The study included four male libraries (pre- and post-emergence tassel, whole anthers and pollen) and four female libraries (pre- and post-emergence ear, ear, and ovule). More than identifying specific candidate genes associated with sex differentiation, the study identified not only transcripts unique to each developmental stage but also modules of genes that have similar patterns of expression that may be involved in common regulatory mechanisms. It would be very interesting to compare the libraries from both studies (Li et al., 2015; Davidson et al., 2011) in order to find a common signature for the female flower differentiation program.

Differential regulation of miRNAs and epigenetic modifications have emerged as potential sex determinants (Parkinson et al., 2007; Martin et al., 2009; Song et al., 2015). Epigenetic mechanisms involved in sex determination were mentioned in melon (Martin et al., 2009) but have been also described in other species bearing unisexual flowers. In maize, the factor Rmr6 maintain repressed epigenetic stages and, consequently, the monoecious sexual system of maize is preserved by limiting the function of the pistil-protecting factor, SILKLESS1, from the apical inflorescence (Parkinson et al., 2007). Deep sequencing of male and female flowers of an andromonoecious poplar allowed the identification of more than 100 miRNAs differentially expressed between the male and female libraries with at least five miRNAs targeting transcripts located in the $P$. tricocharpa sex chromosome, that are involved in several plant development processes from disease resistance to hormonal regulation (Song et al., 2013b). It is worth mentioning that some miRNAs target epigenetic regulators, and are, in turn, regulated by epigenetic modifications, suggesting a feedback between different mechanisms in the control of sex differentiation (Song et al., 2015, 2013b). Another study used the imperfect flowers that naturally occur in the Japanese apricot (Prunus mume) to identify several miRNAs that are unique and associated specifically to pistil development (Gao et al., 2012; Shi et al., 2012).

\section{ENVIRONMENTAL CONTROL OF UNISEXUAL FLOWER DEVELOPMENT}

In $Q$. suber, the emergence of male and female flowers are spatially and temporally separated, with the female flowers emerging at least a month later than the male flowers. In some years, a flush of male flowering is observed again in late summer. On the other hand, the spatial distribution of Q. suber flowers is somehow difficult to predict as, on the same tree, not all the branches exhibit flowers and there are years that only one type of flowers (or none at all) develop. Therefore, it is possible that the induction of these unisexual flowers is under environmental control and might be mediated by epigenetic regulation.

The effect of environmental factors on flower sex ratio in plants has long been the subject of studies of many scientists (Harper, 1907), and some proposed that the environment may influence the evolution of single factor sex-determining systems (reviewed in Charlesworth, 2013). Many other authors have tried to analyze how flower-organ developmental pathways are under the influence of abiotic and biotic factors (e.g., Stehlik et al., 2008). For instance, sex determination in the monoecious oil 
palm is strongly influenced by environmental factors (reviewed in Adam et al., 2011) and dioecious S. oleraceae plants grown under water restriction displayed a male-biased sex ratio (Freeman and Vitale, 1985). Day length and light intensity also affect sex ratio in plant populations. Atriplex halimus (Chenopodiaceae), a monoecious species (and sometimes polygamous), displays increased femaleness under short days and low-light irradiance (Talamali et al., 2003). Therefore, the susceptibility of some plant species to alter their sex-developmental pathways in response to external stimuli suggests that there is a strong interaction between the environmental parameters and genetic regulatory mechanisms. It is possible that small environmental changes such as abiotic stress, day length or temperature may alter epigenetic marks to generate a particular flower sex phenotype. The link between environmental signals, DNA methylation or other epigenetic signatures and plant sex determination has not yet been established, but future studies should explore this further.

\section{WHAT LIES AHEAD?}

The suppression of male and female functions in flowering plants has evolved more than 1000 times (reviewed in Renner, 2014) giving rise to unisexual flowering systems that promote outbreeding and are considered a driving force in plant evolution. However, the development of a unisexual flower has several biological implications, some of which may culminate in failure to produce progeny. Several economically important species have unisexual flowers (e.g., Actinidia deliciosa, Carica papaya, Diospyros lotus) and that poses a problem for producers with several reports suggesting low profitability due to short number of female flowers and consequent decrease in seed production (e.g., Jatropha curcas). Similarly, the production of acorns in Q. suber is difficult to predict because in some years an individual tree might only develop one type of unisexual flower. Thus, the identification of female- and male-determining pathways that trigger the formation of unisexual flowers within the same or in different individuals is an important step to maximize agricultural returns.

Several genetic studies have provided a framework in which several genes were identified as part of sex-determining pathways in distant related species. For instance, recently, a genetic model for sex determination in C. melo and C. sativus, integrating genes that control ethylene kinetics, shed light in how male and female flowers coexist, and how the ratio of male to female flower can be modulated in the same plant in these Cucurbitaceae species (Boualem et al., 2015). However, for other species, such as Q. suber, a long life cycle makes it difficult the use of genetics to uncover mechanisms of flower genderdetermination. The advent of high-throughput technologies, and the generation of large-scale data in non-model species, was a turning point in uncovering potential genes involved in unisexual flower development. However, in most of these studies, the identification of specific genes involved in sex determination was not achieved. Some reasons for this may be that, for most flower tissues being utilized, sex determination has already occurred (Table 1), or that the developmental stages reflecting real sex-determining switch points have not been sampled.
Therefore, a description of the biological samples sequenced and the stages of organ abortion in each species must be really well documented and taken into consideration in the experimental design.

The independent origin of unisexual flowers across angiosperms along with the varied developmental pathways and stages to achieve unisexuality guarantees that there will be no universal genetic program that regulates unisexual flower determination. However, transcriptomic studies have been providing valuable information on the genes and pathways that are differentially involved in male and female flower development for each species, and provide an excellent platform for future functional research. Most of these studies generate a list of genes that are differentially expressed between libraries and then only pinpoint some genes amongst these that have previously reported functions in the same or in other species. This approach leaves out many genes potentially important and thorough unbiased analysis should provide many more new genes involved in the process. Future studies should try to integrate direct comparison of libraries from different studies (those reviewed in Table 1 and others), especially if using phylogenetically close species, or species with similar stages of flower organ abortion, which will uncover potential similar processes involved in sex-determining switch points, as well as downstream, tissue-specific modules regulating male and female flower organ developmental pathways.

The transcriptomic data of early and late stages of male and female flower development of $Q$. suber provides a new tool for studies of unisexual flower development by inception. Temporal and spatial separation of male and female flowers in this species enabled the identification of genes potentially involved in the differentiation of each flower type within the same genetic background. Several questions are still open for discussion namely the mechanisms associated with the induction of each type of flowers at different time points during the reproductive season. The cork oak susceptibility to alter its sex-developmental pathways at different times during the year suggests that the induction of these unisexual flowers is under environmental control, as observed in other species such as spinach (dioecious; Freeman and Vitale, 1985), oil palm or Atriplex halimus (monoecious; reviewed in Talamali et al., 2003; Adam et al., 2011). However, it is unclear how the environmental factors influence the triggering of specific sexdetermining pathways. As the activity of genes is capable of being modified in response to environmental changes by epigenetic control (Turner, 2009), the relationship between environmental signals, DNA methylation and plant organ determination must be addressed.

Moreover, future studies toward the understanding of specific flower organ determining pathways should involve not only the generation of databases based the transcriptomic data for each species flower tissues with the integration of potential known regulatory networks but also be combined with molecular biology experiments (e.g., in situ hybridization, yeast-one-hybrid, yeast-two-hybrid, epigenetic analysis) performed during and preferentially before the first signs of organ differentiation (or abortion) in order to predict sex-determination related mechanisms. 


\section{AUTHOR CONTRIBUTIONS}

All authors listed, have made substantial, direct and intellectual contribution to the work, and approved it for publication.

\section{ACKNOWLEDGMENTS}

This work was funded by FEDER funds through the Operational Competitiveness Programme-COMPETE and by National Funds

\section{REFERENCES}

Adam, H., Collin, M., Richaud, F., Beulé, T., Cros, D., Omoré, A., et al. (2011). Environmental regulation of sex determination in oil palm: current knowledge and insights from other species. Ann. Bot. 108, 1529-1537. doi: 10.1093/aob/mcr151

Adam, H., Jouannic, S., Escoute, J., Duval, Y., Verdeil, J.-L., and Tregear, J. W. (2005). Reproductive developmental complexity in the african oil palm (Elaeis guineensis, Arecaceae). Am. J. Bot. 92, 1836-1852. doi: 10.3732/ajb.92.11.1836

Ainsworth, C. (2000). Boys and girls come out to play: the molecular biology of dioecious plants. Ann. Bot. 86, 211-221. doi: 10.1006/anbo.2000.1201

Akagi, T., Henry, I. M., Tao, R., and Comai, L. (2014). A Y-chromosome-encoded small RNA acts as a sex determinant in persimmons. Science 346, 646-650. doi: $10.1126 /$ science. 1257225

Alvarez-Buylla, E. R., Azpeitia, E., Barrio, R., Benítez, M., and Padilla-Longoria, P. (2010). From ABC genes to regulatory networks, epigenetic landscapes and flower morphogenesis: making biological sense of theoretical approaches. Semin. Cell Dev. Biol. 21, 108-117. doi: 10.1016/j.semcdb.2009.11.010

Andrés, F., and Coupland, G. (2012). The genetic basis of flowering responses to seasonal cues. Nat. Rev. Genet. 13, 627-639. doi: 10.1038/nrg3291

Baggiolini, M. (1952). Stades repères de l'abricotier. Rev. Romande Agric. Vitic. Arboric 8, 28-29.

Bai, S. L., Peng, Y. B., Cui, J. X., Gu, H. T., Xu, L. Y., Li, Y. Q., et al. (2004). Developmental analyses reveal early arrests of the spore-bearing parts of reproductive organs in unisexual flowers of cucumber (Cucumis sativus L.). Planta 220, 230-240. doi: 10.1007/s00425-004-1342-2

Barrett, S. C. H. (2010). Understanding plant reproductive diversity. Philos. Trans. R. Soc. Lond. B Biol. Sci. 365, 99-109. doi: 10.1098/rstb.2009.0199

Bensen, R. J., Johal, G. S., Crane, V. C., Tossberg, J. T., Schnable, P. S., Meeley, R. B., et al. (1995). Cloning and characterization of the maize Anl gene. Plant Cell 7, 75-84. doi: 10.1105/tpc.7.1.75

Bergero, R., and Charlesworth, D. (2011). Preservation of the Y transcriptome in a 10-million-year-old plant sex chromosome system. Curr. Biol. 21, 1470-1474. doi: 10.1016/j.cub.2011.07.032

Boavida, L. C., Varela, M. C., and Feijó, J. A. (1999). Sexual reproduction in the cork oak (Quercus suber L.). I. The progamic phase. Sex. Plant Reprod. 11, 347-353. doi: $10.1007 / \mathrm{s} 004970050162$

Boualem, A., Fergany, M., Fernandez, R., Troadec, C., Martin, A., Morin, H., et al. (2008). A conserved mutation in an ethylene biosynthesis enzyme leads to andromonoecy in melons. Science 321, 836-838. doi: 10.1126/science.11 59023

Boualem, A., Troadec, C., Camps, C., Lemhemdi, A., Morin, H., Sari, M.-A., et al. (2015). A cucurbit androecy gene reveals how unisexual flowers develop and dioecy emerges. Science 350, 688-691. doi: 10.1126/science.aac8370

Bowman, J. L., Alvarez, J., Weigel, D., Meyerowitz, E. M., and Smyth, D. R. (1993). Control of flower development in Arabidopsis thaliana by APETALA1 and interacting genes. Development 119, 721-743.

Bowman, J. L., Smyth, D. R., and Meyerowitz, E. M. (1989). Genes directing flower development in Arabidopsis. Plant Cell 1, 37-52. doi: 10.1105/tpc.1.1.37

Bowman, J. L., Smyth, D. R., and Meyerowitz, E. M. (2012). The ABC model of flower development: then and now. Development 139, 4095-4098. doi: 10.1242/dev.083972

Caporali, E., Carboni, A., Galli, M. G. M., Rossi, G., Spada, A., and Marziani Longo, G. P. (1994). Development of male and female flower in Asparagus officinalis. through FCT-Fundação para a Ciência e a Tecnologia under the project FCOMP-01-0124-FEDER-019461 (PTDC/AGRGPL/118508/2010) and the sub-project SOBREIRO/0019/2009 within the National Consortium (COEC-Cork Oak ESTs Consortium). RS was supported by funding from FCT with a PhD grant (ref. SFRH/BD/84365/2012). HS was supported by funding from FCT with a $\mathrm{PhD}$ grant (ref. SFRH/BD/111529/2015). MC was supported by funding from FCT with a grant SFRH/BSAB/113781/2015.

Search for point of transition from hermaphroditic to unisexual developmental pathway. Sex. Plant Reprod. 7, 239-249. doi: 10.1007/BF00232743

Caporali, E., Spada, A., Marziani, G., Failla, O., and Scienza, A. (2003). The arrest of development of abortive reproductive organs in the unisexual flower of Vitis vinifera ssp. silvestris. Sex. Plant Reprod. 15, 291-300. doi: 10.1007/s00497-0030169-5

Charlesworth, B., and Charlesworth, D. (1978). A model for the evolution of dioecy and gynodioecy. Am. Nat. 112, 975. doi: 10.1086/283342

Charlesworth, D. (2013). Plant sex chromosome evolution. J. Exp. Bot. 64, 405-420. doi: $10.1093 /$ jxb/ers322

Chávez Montes, R. A., Herrera-Ubaldo, H., Serwatowska, J., and de Folter, S. (2015). Towards a comprehensive and dynamic gynoecium gene regulatory network. Curr. Plant Biol. 3-4, 3-12. doi: 10.1016/j.cpb.2015.08.002

Cheng, H., Qin, L., Lee, S., Fu, X., Richards, D. E., Cao, D., et al. (2004). Gibberellin regulates Arabidopsis floral development via suppression of DELLA protein function. Development 131, 1055-1064. doi: 10.1242/dev.00992

Chibalina, M. V., and Filatov, D. A. (2011). Plant Y chromosome degeneration is retarded by haploid purifying selection. Curr. Biol. 21, 1475-1479. doi: 10.1016/j.cub.2011.07.045

Chuck, G., Meeley, R. B., and Hake, S. (1998). The control of maize spikelet meristem fate by the APETALA2-like gene indeterminate spikelet1. Genes Dev. 12, 1145-1154. doi: 10.1101/gad.12.8.1145

Chuck, G., Meeley, R., Irish, E., Sakai, H., and Hake, S. (2007). The maize tasselseed 4 microRNA controls sex determination and meristem cell fate by targeting Tasselseed6/indeterminate spikelet1. Nat. Genet. 39, 1517-1521. doi: 10.1038/ng.2007.20

Coen, E. S., and Meyerowitz, E. M. (1991). The war of the whorls: genetic interactions controlling flower development. Nature 353, 31-37. doi: 10.1038/353031a0

Cruden, R. W., and Hermann-Parker, S. M. (1977). Temporal dioecism: an alternative to dioecism. Evolution 31, 863-866. doi: 10.2307/2407448

Davidson, R. M., Hansey, C. N., Gowda, M., Childs, K. L., Lin, H., Vaillancourt, B., et al. (2011). Utility of RNA sequencing for analysis of maize reproductive transcriptomes. Plant Genome J. 4, 191. doi: 10.3835/plantgenome2011.05.0015

Diggle, P. K., Di Stilio, V. S., Gschwend, A. R., Golenberg, E. M., Moore, R. C., Russell, J. R. W., et al. (2011). Multiple developmental processes underlie sex differentiation in angiosperms. Trends Genet. 27, 368-376. doi: 10.1016/j.tig.2011.05.003

Di Stilio, V. S., Kramer, E. M., and Baum, D. (2005). Floral MADS box genes and homeotic gender dimorphism in Thalictrum dioicum (Ranunculaceae) a new model for the study of dioecy. Plant J. 41, 755-766. doi: 10.1111/j.1365313X.2005.02336.x

Dorsey, M. J. (1912). Variation in the floral structures of Vitis. Bull. Torrey Bot. Club 39, 37-52. doi: 10.2307/2478974

Dorsey, M. J. (1914). Pollen development in the grape with special reference to sterility. Minnesota Agric. Exp. Stn. Bull. 144, 1-60.

Eveland, A. L., Satoh-Nagasawa, N., Goldshmidt, A., Meyer, S., Beatty, M., Sakai, H., et al. (2010). Digital gene expression signatures for maize development. Plant Physiol. 154, 1024-1039. doi: 10.1104/pp.110.159673

Feng, S., Martinez, C., Gusmaroli, G., Wang, Y., Zhou, J., Wang, F., et al. (2008). Coordinated regulation of Arabidopsis thaliana development by light and gibberellins. Nature 451, 475-479. doi: 10.1038/nature06448

Flanagan, C. A., Hu, Y., and Ma, H. (1996). Specific expression of the AGL1 MADS-box gene suggests regulatory functions in Arabidopsis gynoecium and 
ovule development. Plant J. 10, 343-353. doi: 10.1046/j.1365-313X.1996.1002 0343.x

Freeman, D. C., and Vitale, J. J. (1985). The influence of environment on the sex ratio and fitness of spinach. Bot. Gaz. 146, 137-142. doi: 10.1086/337508

Gao, P., Sheng, Y., Luan, F., Ma, H., and Liu, S. (2015). RNA-seq transcriptome profiling reveals differentially expressed genes involved in sex expression in melon. Crop Sci. 55, 1686-1695. doi: 10.2135/cropsci2014.06.0444

Gao, Z., Shi, T., Luo, X., Zhang, Z., Zhuang, W., and Wang, L. (2012). Highthroughput sequencing of small RNAs and analysis of differentially expressed microRNAs associated with pistil development in Japanese apricot. BMC Genomics 13:371. doi: 10.1186/1471-2164-13-371

Grant, S., Hunkirchen, B., and Saedler, H. (1994). Developmental differences between male and female flowers in the dioecious plant Silene Latifolia. Plant J. 6, 471-480. doi: 10.1046/j.1365-313X.1994.6040471.x

Greenup, A., Peacock, W. J., Dennis, E. S., and Trevaskis, B. (2009). The molecular biology of seasonal flowering-responses in Arabidopsis and the cereals. Ann. Bot. 103, 1165-1172. doi: 10.1093/aob/mcp063

Guo, S., Zheng, Y., Joung, J.-G., Liu, S., Zhang, Z., Crasta, O. R., et al. (2010). Transcriptome sequencing and comparative analysis of cucumber flowers with different sex types. BMC Genomics 11:384. doi: 10.1186/1471-2164-11-384

Harkess, A., Mercati, F., Shan, H. Y., Sunseri, F., Falavigna, A., and Leebens-Mack, J. (2015). Sex-biased gene expression in dioecious garden asparagus (Asparagus officinalis). New Phytol. 207, 883-892. doi:10.1111/nph.13389

Harper, R. A. (1907). Sex-determining factors in plants. Science 25, 379-382.

Helliwell, C. A., Chandler, P. M., Poole, A., Dennis, E. S., and Peacock, W. J. (2001). The CYP88A cytochrome P450, ent-kaurenoic acid oxidase, catalyzes three steps of the gibberellin biosynthesis pathway. Proc. Natl. Acad. Sci. U.S.A. 98, 2065-2070. doi: 10.1073/pnas.98.4.2065

Hou, J.-H., Gao, Z.-H., Zhang, Z., Chen, S.-M., Ando, T., Zhang, J.-Y., et al. (2011). Isolation and characterization of an AGAMOUS homologue PmAG from the Japanese Apricot (Prunus mume Sieb. et Zucc.). Plant Mol. Biol. Rep. 29, 473-480. doi: 10.1007/s11105-010-0248-3

Huang, Y.-J., Liu, L.-L., Huang, J.-Q., Wang, Z.-J., Chen, F.-F., Zhang, Q.-X., et al. (2013). Use of transcriptome sequencing to understand the pistillate flowering in hickory (Carya cathayensis Sarg.). BMC Genomics 14:691. doi: 10.1186/1471-2164-14-691

Jaligot, E., Beulé, T., Baurens, F.-C., Billotte, N., and Rival, A. (2004). Search for methylation-sensitive amplification polymorphisms associated with the mantled variant phenotype in oil palm (Elaeis guineensis Jacq). Genome 47, 224-228. doi: 10.1139/g03-085

Kakumanu, A., Ambavaram, M. M. R., Klumas, C., Krishnan, A., Batlang, U., Myers, E., et al. (2012). Effects of drought on gene expression in maize reproductive and leaf meristem tissue revealed by RNA-seq. Plant Physiol. 160, 846-867. doi: 10.1104/pp.112.200444

Kanazashi, T., and Kanazashi, A. (2003). Estimation for the timing of the internal developmental processes of acorns from fruit size in Quercus serrata Thunb. ex Murray. J. For. Res. 8, 261-266. doi: 10.1007/s10310-003-0035-1

Kater, M. M., Franken, J., Carney, K. J., Colombo, L., and Angenent, G. C. (2001). Sex determination in the monoecious species cucumber is confined to specific floral whorls. Plant Cell 13, 481-493. doi: 10.1105/tpc.13.3.481

Knopf, R. R., and Trebitsh, T. (2006). The female-specific Cs-ACS1G gene of cucumber. A case of gene duplication and recombination between the nonsex-specific 1-aminocyclopropane-1-carboxylate synthase gene and a branchedchain amino acid transaminase gene. Plant Cell Physiol. 47, 1217-1228. doi: $10.1093 / \mathrm{pcp} / \mathrm{pcj} 092$

Larue, N. C., Sullivan, A. M., and Di Stilio, V. S. (2013). Functional recapitulation of transitions in sexual systems by homeosis during the evolution of dioecy in Thalictrum. Front. Plant Sci. 4:487. doi: 10.3389/fpls.2013.00487

Latchman, D. S. (1997). Transcription factors: an overview. Int. J. Biochem. Cell Biol. 29, 1305-1312. doi: 10.1016/S1357-2725(97)00085-X

Le Roux, L. G., and Kellogg, E. A. (1999). Floral development and the formation of unisexual spikelets in the Andropogoneae (Poaceae). Am. J. Bot. 86, 354-366. doi: $10.2307 / 2656757$

Li, S. F., Zhang, G. J., Yuan, J. H., Deng, C. L., Lu, L. D., and Gao, W. J. (2015). Effect of 5-azaC on the growth, flowering time and sexual phenotype of spinach. Russ. J. Plant Physiol. 62, 670-675. doi: 10.1134/S1021443715050118

Li, Z., Wang, S., Tao, Q., Pan, J., Si, L., Gong, Z., et al. (2012). A putative positive feedback regulation mechanism in CsACS2 expression suggests a modified model for sex determination in cucumber (Cucumis sativus L.). J. Exp. Bot. 63, 4475-4484. doi: 10.1093/jxb/ers123

Liljegren, S. J., Ditta, G. S., Eshed, Y., Savidge, B., Bowman, J. L., and Yanofsky, M. F. (2000). SHATTERPROOF MADS-box genes control seed dispersal in Arabidopsis. Nature 404, 766-770. doi: 10.1038/35008089

Litt, A., and Kramer, E. M. (2010). The ABC model and the diversification of floral organ identity. Semin. Cell Dev. Biol. 21, 129-137. doi: 10.1016/j.semcdb.2009.11.019

Liu, H., Yang, X., Liao, X., Zuo, T., Qin, C., Cao, S., et al. (2015). Genome-wide comparative analysis of digital gene expression tag profiles during maize ear development. Genomics 106, 52-60. doi: 10.1016/j.ygeno.2015.03.005

Liu, J., Yin, T., Ye, N., Chen, Y., Yin, T., Liu, M., et al. (2013). Transcriptome analysis of the differentially expressed genes in the male and female shrub Willows (Salix suchowensis). PLoS ONE 8:e60181. doi: 10.1371/journal.pone.0060181

Martin, A., Troadec, C., Boualem, A., Rajab, M., Fernandez, R., Morin, H., et al. (2009). A transposon-induced epigenetic change leads to sex determination in melon. Nature 461, 1135-1138. doi: 10.1038/nature08498

Mibus, H., and Tatlioglu, T. (2004). Molecular characterization and isolation of the $F / f$ gene for femaleness in cucumber (Cucumis sativus L.). Theor. Appl. Genet. 109, 1669-1676. doi: 10.1007/s00122-004-1793-7

Mitchell, C. H., and Diggle, P. K. (2005). The evolution of unisexual flowers: morphological and functional convergence results from diverse developmental transitions. Am. J. Bot. 92, 1068-1076. doi: 10.3732/ajb.92.7.1068

Muyle, A., Zemp, N., Deschamps, C., Mousset, S., Widmer, A., and Marais, G. A. B. (2012). Rapid de novo evolution of X chromosome dosage compensation in Silene latifolia, a plant with young sex chromosomes. PLoS Biol. 10:e1001308. doi: 10.1371/journal.pbio.1001308

Ó'Maoiléidigh, D. S., Graciet, E., and Wellmer, F. (2014). Gene networks controlling Arabidopsis thaliana flower development. New Phytol. 201, 16-30. doi: 10.1111/nph.12444

Ong-Abdullah, M., Ordway, J. M., Jiang, N., Ooi, S.-E., Kok, S.-Y., Sarpan, N., et al. (2015). Loss of Karma transposon methylation underlies the mantled somaclonal variant of oil palm. Nature 525, 533-537. doi: 10.1038/nature 15365

Parkinson, S. E., Gross, S. M., and Hollick, J. B. (2007). Maize sex determination and abaxial leaf fates are canalized by a factor that maintains repressed epigenetic states. Dev. Biol. 308, 462-473. doi: 10.1016/j.ydbio.2007. 06.004

Pelaz, S., Ditta, G. S., Baumann, E., Wisman, E., and Yanofsky, M. F. (2000). B and $\mathrm{C}$ floral organ identity functions require SEPALLATA MADS-box genes. Nature 405, 200-203. doi: 10.1038/35012103

Pfent, C., Pobursky, K. J., Sather, D. N., and Golenberg, E. M. (2005). Characterization of SPAPETALA3 and SPPISTILLATA, B class floral identity genes in Spinacia oleracea, and their relationship to sexual dimorphism. Dev. Genes Evol. 215, 132-142. doi: 10.1007/s00427-004-0459-4

Plackett, A. R. G., Thomas, S. G., Wilson, Z. A., and Hedden, P. (2011). Gibberellin control of stamen development: a fertile field. Trends Plant Sci. 16, 568-578. doi: 10.1016/j.tplants.2011.06.007

Ramos, M. J. N., Coito, J. L., Silva, H. G., Cunha, J., Costa, M. M. R., and Rocheta, M. (2014). Flower development and sex specification in wild grapevine. BMC Genomics 15:1095. doi: 10.1186/1471-2164-15-1095

Renner, S. S. (2014). The relative and absolute frequencies of angiosperm sexual systems: D ioecy, monoecy, gynodioecy, and an updated online database. Am. J. Bot. 101, 1588-1596. doi: 10.3732/ajb.1400196

Rocheta, M., Sobral, R., Magalhães, J., Amorim, M. I., Ribeiro, T., Pinheiro, M., et al. (2014). Comparative transcriptomic analysis of male and female flowers of monoecious Quercus suber. Front. Plant Sci. 5:599. doi: 10.3389/fpls.2014.00599

Ronse Decraene, L. P., and Smets, E. F. (1999). The floral development and anatomy of Carica papaya (Caricaceae). Can. J. Bot. 77, 582-598. doi: $10.1139 / \mathrm{b} 99-026$

Rudich, J. (1990). "Biochemical aspects of hormonal regulation of sex expression in Cucurbits," in Biology and Utilization of the Cucurbitaceae, eds D. M. Bates, R. W. Robinson, and C. Jeffrey (Ithaca, NY: Cornell University Press), 269-280.

Rudich, J., Halevy, A. H., and Kedar, N. (1972). Ethylene evolution from cucumber plants as related to sex expression. Plant Physiol. 49, 998-999. doi: $10.1104 /$ pp.49.6.998 
Sather, D. N., Jovanovic, M., and Golenberg, E. M. (2010). Functional analysis of $\mathrm{B}$ and $\mathrm{C}$ class floral organ genes in spinach demonstrates their role in sexual dimorphism. BMC Plant Biol. 10:46. doi: 10.1186/1471-2229-10-46

Sekhon, R. S., Briskine, R., Hirsch, C. N., Myers, C. L., Springer, N. M., Buell, C. R., et al. (2013). Maize gene atlas developed by RNA sequencing and comparativee evaluation of transcriptomes based on RNA sequencing and microarrays. PLoS ONE 8:e61005. doi: 10.1371/journal.pone.0061005

Sheppard, L. A., Brunner, A. M., Krutovskii, K. V., Rottmann, W. H., Skinner, J. S., Vollmer, S. S., et al. (2000). A DEFICIENS homolog from the dioecious tree black cottonwood is expressed in female and male floral meristems of the two-whorled, unisexual flowers. Plant Physiol. 124, 627-640. doi: 10.1104/pp.124.2.627

Shi, T., Gao, Z., Wang, L., Zhang, Z., Zhuang, W., Sun, H., et al. (2012). Identification of differentially-expressed genes associated with pistil abortion in Japanese apricot by genome-wide transcriptional analysis. PLoS ONE 7:e47810. doi: 10.1371/journal.pone.0047810

Song, Y., Ma, K., Ci, D., Chen, Q., Tian, J., and Zhang, D. (2013a). Sexual dimorphic floral development in dioecious plants revealed by transcriptome, phytohormone, and DNA methylation analysis in Populus tomentosa. Plant Mol. Biol. 83, 559-576. doi: 10.1007/s11103-013-0108-2

Song, Y., Ma, K., Ci, D., Zhang, Z., and Zhang, D. (2013b). Sexual dimorphism floral microRNA profiling and target gene expression in andromonoecious poplar (Populus tomentosa). PLOS ONE 8:e62681. doi: 10.1371/journal.pone.0062681

Song, Y., Tian, M., Ci, D., and Zhang, D. (2015). Methylation of microRNA genes regulates gene expression in bisexual flower development in andromonoecious poplar. J. Exp. Bot. 66, 1891-1905. doi: 10.1093/jxb/eru531

Stehlik, I., Friedman, J., and Barrett, S. C. H. (2008). Environmental influence on primary sex ratio in a dioecious plant. Proc. Natl. Acad. Sci. U.S.A. 105, 10847-10852. doi: 10.1073/pnas.0801964105

Sun, J.-J., Li, F., Li, X., Liu, X.-C., Rao, G.-Y., Luo, J.-C., et al. (2010). Why is ethylene involved in selective promotion of female flower development in cucumber? Plant Signal. Behav. 5, 1052-1056. doi: 10.4161/psb.5.8.12411

Talamali, A., Bajji, M., Le Thomas, A., Kinet, J. M., and Dutuit, P. (2003). Flower architecture and sex determination: how does Atriplex halimus play with floral morphogenesis and sex genes? New Phytol. 157, 105-113. doi: 10.1046/j.14698137.2003.00651.x

Tanurdzic, M., and Banks, J. A. (2004). Sex-determining mechanisms in land plants. Plant Cell 16(Suppl.), S61-S71. doi: 10.1105/tpc.016667

Theissen, G., and Melzer, R. (2007). Molecular mechanisms underlying origin and diversification of the angiosperm flower. Ann. Bot. 100, 603-619. doi: $10.1093 / \mathrm{aob} / \mathrm{mcm} 143$

Turner, B. M. (2009). Epigenetic responses to environmental change and their evolutionary implications. Philos. Trans. R. Soc. Lond. B Biol. Sci. 364, 3403-3418. doi: 10.1098/rstb.2009.0125
Urasaki, N., Tarora, K., Shudo, A., Ueno, H., Tamaki, M., Miyagi, N., et al. (2012). Digital transcriptome analysis of putative sex-determination genes in papaya (Carica papaya). PLoS ONE 7:e40904. doi: 10.1371/journal.pone. 0040904

Varela, M. C., and Valdiviesso, T. (1996). Phenological phases of Quercus suber L. flowering. For. Genet. 3, 93-102.

Wang, X., Elling, A. A., Li, X., Li, N., Peng, Z., He, G., et al. (2009). Genomewide and organ-specific landscapes of epigenetic modifications and their relationships to mRNA and small RNA transcriptomes in maize. Plant J. 21, 1053-1069. doi: 10.1105/tpc.109.065714

Wellmer, F., Riechmann, J. L., Alves-Ferreira, M., and Meyerowitz, E. M. (2004). Genome-wide analysis of spatial gene expression in Arabidopsis flowers. Plant Cell 16, 1314-1326. doi: 10.1105/tpc.021741

Winkler, R. G., and Helentjaris, T. (1995). The maize Dwarf3 gene encodes a cytochrome P450-mediated early step in Gibberellin biosynthesis. Plant Cell 7, 1307-1317. doi: 10.1105/tpc.7.8.1307

Wu, T., Qin, Z., Zhou, X., Feng, Z., and Du, Y. (2010). Transcriptome profile analysis of floral sex determination in cucumber. J. Plant Physiol. 167, 905-913. doi: 10.1016/j.jplph.2010.02.004

Yamasaki, S., Fujii, N., Matsuura, S., Mizusawa, H., and Takahashi, H. (2001). The $M$ locus and ethylene-controlled sex determination in andromonoecious cucumber plants. Plant Cell Physiol. 42, 608-619. doi: 10.1093/pcp/ pce076

Zhang, X., Feng, B., Zhang, Q., Zhang, D., Altman, N., and Ma, H. (2005). Genome-wide expression profiling and identification of gene activities during early flower development in Arabidopsis. Plant Mol. Biol. 58, 401-419. doi: 10.1007/s11103-005-5434-6

Zhang, Y., Liu, B., Yang, S., An, J., Chen, C., Zhang, X., et al. (2014). A cucumber DELLA homolog CsGAIP may inhibit staminate development through transcriptional repression of B class floral homeotic genes. PLoS ONE 9:e91804. doi: 10.1371/journal.pone.0091804

Zhu, Y., Fu, J., Zhang, J., Liu, T., Jia, Z., Wang, J., et al. (2009). Genome-wide analysis of gene expression profiles during ear development of maize. Plant Mol. Biol. 70, 63-77. doi: 10.1007/s11103-009-9457-2

Conflict of Interest Statement: The authors declare that the research was conducted in the absence of any commercial or financial relationships that could be construed as a potential conflict of interest.

Copyright (c) 2016 Sobral, Silva, Morais-Cecílio and Costa. This is an open-access article distributed under the terms of the Creative Commons Attribution License (CC $B Y)$. The use, distribution or reproduction in other forums is permitted, provided the original author(s) or licensor are credited and that the original publication in this journal is cited, in accordance with accepted academic practice. No use, distribution or reproduction is permitted which does not comply with these terms. 